\title{
Vitamin E Biosynthesis and Its Regulation in Plants
}

\author{
Laurent Mène-Saffrané
}

Department of Biology, University of Fribourg, Chemin du Musée, 10, 1700 Fribourg, Switzerland; laurent.mene-saffrane@unifr.ch; Tel.: +41-268-008-808

Received: 19 November 2017; Accepted: 21 December 2017; Published: 25 December 2017

\begin{abstract}
Vitamin $\mathrm{E}$ is one of the 13 vitamins that are essential to animals that do not produce them. To date, six natural organic compounds belonging to the chemical family of tocochromanols-four tocopherols and two tocotrienols-have been demonstrated as exhibiting vitamin $\mathrm{E}$ activity in animals. Edible plant-derived products, notably seed oils, are the main sources of vitamin $\mathrm{E}$ in the human diet. Although this vitamin is readily available, independent nutritional surveys have shown that human populations do not consume enough vitamin E, and suffer from mild to severe deficiency. Tocochromanols are mostly produced by plants, algae, and some cyanobacteria. Tocochromanol metabolism has been mainly studied in higher plants that produce tocopherols, tocotrienols, plastochromanol-8, and tocomonoenols. In contrast to the tocochromanol biosynthetic pathways that are well characterized, our understanding of the physiological and molecular mechanisms regulating tocochromanol biosynthesis is in its infancy. Although it is known that tocochromanol biosynthesis is strongly conditioned by the availability in homogentisate and polyprenyl pyrophosphate, its polar and lipophilic biosynthetic precursors, respectively, the mechanisms regulating their biosyntheses are barely known. This review summarizes our current knowledge of tocochromanol biosynthesis in plants, and highlights future challenges regarding the understanding of its regulation.
\end{abstract}

Keywords: vitamin E; tocochromanol; tocopherol; tocotrienol; plastochromanol-8; tocomonoenol; homogentisate; polyprenyl pyrophosphate; nutrigenomics

\section{Introduction}

Natural compounds exhibiting vitamin E activity in animal cells belong to the chemical family of tocochromanols, a group of organic molecules with a polar chromanol ring and lipophilic polyprenyl side chain that varies according to the type of tocochromanol [1]. The polyprenyl precursor of tocopherols, tocotrienols, plastochromanol-8 (PC-8), and tocomonoenols is phytyl pyrophosphate (PPP), geranylgeranyl pyrophosphate (GGPP), solanesyl pyrophosphate (SPP), and tetrahydrogeranylgeranyl pyrophosphate (THGGPP), respectively (Figure 1). According to the degree of methylation of the chromanol ring, each type of tocochromanol exhibits up to four different forms, named $\alpha$ - (three-methyl groups), $\beta$ - and $\gamma$ - (two-methyl groups), and $\delta$-tocochromanol (one-methyl group; Figure 1), respectively. While the four forms of tocopherol, tocotrienol, and tocomonoenol have been identified in wild-type plant extracts, only the $\gamma$ - form of the solanesyl-derived tocochromanol PC-8 naturally exists. 


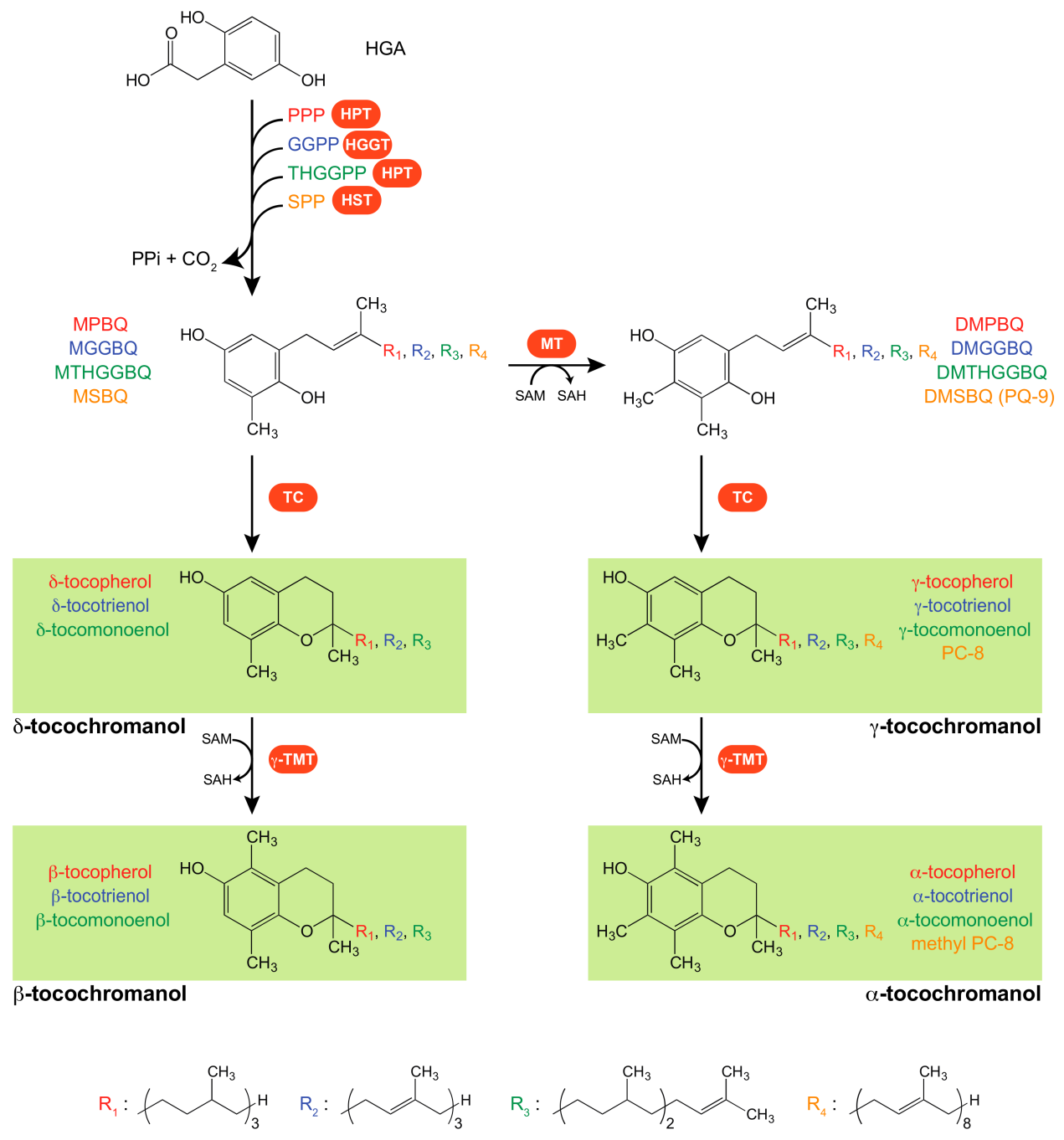

Figure 1. Tocochromanol biosynthetic pathways in plants. Tocochromanol and prenyl benzoquinol chemical structures and biosynthetic enzymes (highlighted in orange). Tocochromanol and prenyl benzoquinol names are color-coded to distinguish each tocochromanol pathway: red for the tocopherol pathway, blue for the tocotrienol pathway, green for the tocomonoenol pathway, and orange for the PC-8 and methyl PC- 8 pathway. The $\alpha-, \beta-, \gamma_{-}$, and $\delta$-forms of tocopherols, tocotrienols, and tocomonoenols have been identified in plants. For solanesyl-derived tocochromanols, only PC- 8 has been identified in wild-type plants, and only methyl PC- 8 has been identified in transgenic Arabidopsis overexpressing the $\gamma$-TMT/VTE4 gene. Abbreviations: HGA, homogentisate; HGGT, homogentisate geranylgeranyltransferase; HPT, homogentisate phytyltransferase; HST, homogentisate solanesyltransferase; GGPP, geranylgeranyl pyrophosphate; $\gamma$-TMT, $\gamma$-tocopherol methyltransferase; MT, methyltransferase; PC-8, plastochromanol-8; PPi, pyrophosphate; PPP, phytyl pyrophosphate; PQ-9, plastoquinol-9; SAM, S-adenosyl-L-methionine; SAH, S-adenosyl-L-homocysteine; SPP, solanesyl pyrophosphate; TC, tocopherol cyclase; THGGPP, tetrahydrogeranylgeranyl pyrophosphate. Prenyl benzoquinol acronyms are detailed in the main text.

The first article published on vitamin E relates the finding of an unknown nutritional factor that prevents embryo resorption during rodent gestation [2]. Several years later, this "factor X", as it was originally named, was identified as $\alpha$-tocopherol [3]. In addition to its essential role in animal reproduction, vitamin $\mathrm{E}$ has been shown to have beneficial roles in human health [4], notably by inhibiting lung cancer [5], by delaying brain aging and reducing the risk of developing Alzheimer's disease [6], and by suppressing cholesterogenesis [7,8]. Although vitamin E is present in many edible plant-derived products, converging nutritional surveys conducted in both poor and developed 
countries, respectively, have shown that a significant proportion of human populations exhibit mild to severe vitamin E deficiencies [9-13]. It has been shown, for instance, that 23\% of the Seoul metropolitan population exhibited plasma $\alpha$-tocopherol concentrations below $12 \mu \mathrm{mol} / \mathrm{L}$, the threshold defining vitamin E deficiency in humans [11]. The consequences of vitamin E deficiency on human health have not yet been fully documented nor investigated. However, it has been clearly established that low plasma vitamin $\mathrm{E}$ is strongly associated with miscarriage during the first trimester of woman pregnancy [12]. Moreover, it has been shown that diet supplementation with vitamin E decreased the miscarriage rate of pregnant woman by approximately $50 \%$ [12]. Collectively, these results demonstrate the importance of adequate vitamin $\mathrm{E}$ intake for proper reproduction.

It has been assumed for a long time that tocochromanol biosynthesis was the exclusive appanage of plants, algae, and some cyanobacteria that are all photosynthetic organisms. However, a recent study showed that Plasmodium falciparum, a non-photosynthetic parasite that causes malaria, synthesizes both $\alpha$ - and $\gamma$-tocopherols during its intraerythrocytic stages to avoid oxidative stress [14-16]. Besides this exception, tocochromanol metabolism has been primarily studied in angiosperms and in the vitamin E-producing cyanobacteria Synechocystis. The present review summarizes our current knowledge on tocochromanol metabolism in plants, including the core tocochromanol biosynthetic pathway that is now well delineated (Section 2); the transcriptional regulation of $\gamma$-TMT expression, which is the gene encoding the biosynthetic enzyme of the most potent vitamin E form of $\alpha$-tocopherol in animals (Section 3); the regulation of homogentisate (HGA) biosynthesis, which is the polar precursor of tocochromanols (Section 4); and the regulation of polyprenyl pyrophosphate biosynthesis, which is the lipophilic precursor of tocochromanols (Section 5). Thus, this work complements the very recent review that highlighted the biosynthetic origins and transports of polar and lipophilic tocochromanol biosynthetic precursors in plants [17].

\section{Tocochromanol Biosynthetic Pathways}

Tocochromanol biosynthesis is initiated by the condensation of the polar aromatic head HGA with various lipophilic polyprenyl pyrophosphates that determine the type of tocochromanol. PPP is the lipophilic biosynthetic precursor of tocopherols, while GGPP is the one for tocotrienols, as is SPP for PC-8, and THGGPP for tocomonoenols (Pellaud and Mène-Saffrané, 2017 [17] and Figure 1). The condensation reaction is catalyzed by three types of HGA prenyltransferases that possess each their substrate specificities. Tocopherol synthesis is initiated by HGA phytyltransferases (HPTs) that condense HGA and PPP. This enzyme has been identified in both Arabidopsis and the cyanobacterium Synechocystis [18,19]. While the Arabidopsis HPT (AtHPT), also named VTE2, preferentially utilizes PPP as a prenyl donor, its Synechocystis counterpart uses both PPP and GGPP [18]. Although AtHPT poorly utilizes GGPP as a substrate in vitro, and wild-type Arabidopsis accessions do not naturally accumulate tocotrienols, it has been shown that AtHPT catalyzes the synthesis of tocotrienols in transgenic Arabidopsis plants that are overaccumulating HGA [20]. Recently, AtHPT was also shown to be catalyzing the accumulation of $\gamma$-tocomonoenol in Arabidopsis seeds, indicating that THGGPP is a substrate for this enzyme [21]. Collectively, these data show that the substrate specificity of HGA phytyl transferases is wider than that originally described, and is notably modulated by HGA availability. In Poaceae, tocotrienol synthesis is initiated by HGA geranylgeranyltransferase (HGGT), which utilizes both GGPP and PPP as prenyl donors in vitro. In addition, overexpression of the barley HGGT gene in the Arabidopsis vte2 mutant induces the quantitative accumulation of both tocotrienols and tocopherols in seeds and leaves, indicating that HGGT utilizes both prenyl donors in vivo as well [22]. The Arabidopsis vte2-1 mutant lacks tocopherols, but still accumulates PC-8 in both seeds and leaves, confirming in vitro data showing that VTE2 is not involved in the condensation of HGA with the solanesyl derivative SPP $[18,23]$. This reaction is catalyzed by the HGA solanesyltransferase (HST) that has been identified in both Chlamydomonas and Arabidopsis [24,25]. The condensation reaction between HGA and polyprenyl pyrophosphates produces 2-methyl-6-phytyl-1,4-benzoquinol (MPBQ) for tocopherols, 2-methyl-6-geranylgeranyl- 
1,4-benzoquinol (MGGBQ) for tocotrienols, 2-methyl-6-solanesyl-1,4-benzoquinol (MSBQ) for PC-8, and 2-methyl-6-tetrahydrogeranylgeranyl-1,4-benzoquinol (MTHGGBQ) for tocomonoenols (Figure 1). These compounds are either direct precursors of $\delta$ - and $\beta$-tocochromanols, or can alternatively be methylated by a methyltransferase (MT/VTE3) that uses S-adenosylL-methionine (SAM) as a methyl donor [26,27]. The products of the later reaction are prenylated dimethyl-benzoquinols, namely 2,3-dimethyl-6-phytyl-1,4-benzoquinol (DMPBQ) for tocopherols, 2,3-dimethyl-6-geranylgeranyl-1,4-benzoquinol (DMGGBQ) for tocotrienols, 2,3-dimethyl-6-solanesyl-1,4-benzoquinol better known as plastoquinol-9 (PQ-9) for PC-8, and 2,3-dimethyl-6-tetrahydrogeranylgeranyl-1,4-benzoquinol (DMTHGGBQ) for tocomonoenols (Figure 1). Both methyl- and dimethyl-benzoquinols are then further cyclized by the tocopherol cyclase (TC/VTE1) into $\delta$ - and $\gamma$-tocochromanols, respectively. Seeds of the Arabidopsis vte1-1 mutant lack all tocopherols, PC-8, and $\gamma$-tocomonoenol, indicating that the cyclase indiscriminately uses monoand dimethyl-benzoquinols carrying either a phytyl, a solanesyl, or a tetrahydrogeranylgeranyl side chain as substrates $[21,23,28,29]$. The fourth and final step of tocochromanol biosynthesis consists of the methylation of $\gamma$ - and $\delta$-tocochromanols into $\alpha$ - and $\beta$-tocochromanols, respectively [30,31]. This reaction is catalyzed by the $\gamma$-tocopherol methyltransferase $(\gamma$-TMT/VTE4) that utilizes SAM as methyl donor (Figure 1). In Arabidopsis leaves and seeds, VTE4 converts $\gamma$ - and $\delta$-tocopherols into $\alpha$ - and $\beta$-tocopherol, respectively, indicating that the methyl transferase efficiently methylates phytyl-derived tocochromanols [30]. In addition, transgenic Arabidopsis lines overexpressing the barley HGGT gene notably produce $\alpha$-tocotrienol [32]. This indicates that the $\gamma$-tocopherol methyltransferase VTE4 catalyzes that methylation of geranylgeranyl-derived tocochromanol such as $\gamma$-tocotrienol as well.

\section{Regulation of the $\gamma$-tocopherol methyltransferase Expression}

The different tocochromanol forms identified in plants do not exhibit the same vitamin $\mathrm{E}$ activity in animal cells [1]. Based on the rat fetal resorption assay, $\alpha$-tocopherol $(1.49 \mathrm{IU} / \mathrm{mg}$; $100 \%)$ is by far the most potent vitamin $\mathrm{E}$ form, followed by $\beta$-tocopherol $(0.75 \mathrm{IU} / \mathrm{mg} ; 50 \%)$, $\alpha$-tocotrienol (0.45-0.75 IU / mg; 30-50\%), $\gamma$-tocopherol (0.15 IU / mg; $10 \%)$, $\beta$-tocotrienol $(0.08 \mathrm{IU} / \mathrm{mg}$; $5 \%$ ), and $\delta$-tocopherol ( $0.05 \mathrm{IU} / \mathrm{mg} ; 3 \%)$. The vitamin $\mathrm{E}$ activities of $\gamma$ - and $\delta$-tocotrienol have been tested and were below the limit of detection, while those of other tocochromanols such as PC- 8 and tocomonoenols have not been tested yet. The difference in vitamin $\mathrm{E}$ activity among tocochromanol forms results from their differential affinities to the $\alpha$-tocopherol transfer protein, a cytoplasmic protein that transports tocochromanols from the endosomal fraction of hepatocytes into the bloodstream of animals $[33,34]$. This implies that at equal molarity, a plant tissue accumulating $\alpha$-tocopherol instead of $\gamma$-tocopherol for instance, exhibits 10 times more vitamin E activity. Based on this, a relevant question regarding the regulation of tocochromanol biosynthesis in plants and the improvement of crops vitamin E activity is: what are the molecular mechanisms regulating $\gamma$-TMT expression?

The main tocochromanol identified in wild-type leaves analyzed to date is $\alpha$-tocopherol, indicating that leaf $\gamma$-TMT/VTE4 activity is sufficient to quantitatively methylate the $\gamma$-tocopherol pool present in this tissue. In contrast, despite the presence of PC-8 ( $\gamma$-tocochromanol) in wild-type Arabidopsis and maize leaves, methyl PC-8 ( $\alpha$-tocochromanol) has not been detected in any wild-type tissue analyzed to date [23]. In contrast, methyl PC-8 accumulates in transgenic Arabidopsis leaves overexpressing $\gamma$-TMT/VTE4, demonstrating that PC-8 is a substrate for $\gamma$-TMT/VTE4, and that endogenous $\gamma$-TMT/VTE4 activity is not sufficient to convert all $\gamma$-tocochromanols into $\alpha$-tocochromanols [35]. This later conclusion is further supported by the tocochromanol composition of transgenic Arabidopsis leaves overexpressing the barley HGGT gene. Indeed, while these transgenic lines accumulate tocopherols mostly under the form of $\alpha$-tocopherol, their tocotrienol pool is mainly under the form of $\gamma$-tocotrienol [32]. In contrast to this, another metabolic engineering study in which tocochromanol biosynthesis has been increased by enhancing the production of HPP in chloroplasts suggests that $\gamma$-TMT activity might be limiting for $\alpha$-tocopherol synthesis in leaves. In comparison to controls, 
these Arabidopsis transgenic lines overaccumulated both $\gamma$-tocopherol and $\gamma$-tocotrienol, but exhibited control levels for $\alpha$-tocopherol in leaves [36]. In addition, they did not accumulate any detectable $\alpha$-tocotrienol, despite the strong accumulation of $\gamma$-tocotrienol in leaf tissues. In alfalfa, it has been shown that the overexpression of a Medicago $\gamma$-TMT modestly but significantly increased $\alpha$-tocopherol accumulation in leaves [37]. Collectively, these data show that the leaf $\gamma$-TMT/VTE4 activity is clearly not sufficient to fully methylate both $\gamma$-tocotrienol and PC-8, and is sometimes limiting $\alpha$-tocopherol biosynthesis. The former conclusion might indicate that $\gamma$-TMT/VTE4 has a lower affinity for $\gamma$-tocotrienol and PC-8 than for $\alpha$-tocopherol.

In contrast to leaves, the tocochromanol composition of wild-type seeds is much more variable, and three groups of plant species can be currently distinguished according to this criterion. The seeds of some plant species accumulate mostly $\gamma$-tocochromanols and very little or no $\alpha$-tocochromanols. This is notably the case of wild-type Arabidopsis seeds, which accumulate mostly $\gamma$-tocopherol and PC-8, very low levels of $\alpha$-tocopherol, and no methyl PC-8 [23]. The overexpression of $\gamma$-TMT genes in Arabidopsis and Brassica napus is sufficient to trigger the quantitative accumulation of both $\alpha$-tocopherol and methyl PC-8 in transgenic seeds, thus demonstrating that the lack of $\alpha$-tocochromanols in the seeds of these species results from the very low transcriptional activity of the $\gamma$-TMT/VTE4 gene in seeds $[30,35,38]$. In contrast to Arabidopsis, the seeds of other plant species mostly accumulate $\alpha$-tocochromanols, and very few $\gamma$-tocochromanols. This is notably the case of sunflower and wheat, which accumulate mostly $\alpha$-tocopherol $\pm \alpha$-tocotrienol, and very low levels of $\gamma$-tocochromanols $[39,40]$. This indicates that the VTE4 activity in seeds of these species is sufficient to quantitatively convert almost all of the $\gamma$-tocochromanols into $\alpha$-tocochromanols. The third type of plants accumulate both $\alpha$ - and $\gamma$-tocochromanols in seeds, suggesting that although their VTE4 activity is sufficient to support the synthesis of $\alpha$-tocochromanols, it is not strong enough to fully methylate the pools of $\gamma$-tocochromanols. This group includes species such as rapeseed and maize [41-43]. Our current knowledge of the transcriptional mechanism(s) regulating $\gamma$-TMT/VTE4 expression, notably in seeds, is currently limited to a single study performed in soybean. Tocopherol analysis in seeds of 1109 wild and cultivated soybean varieties showed that while almost all of them produce primarily $\gamma$-tocopherol, three varieties accumulate up to seven times more $\alpha$-tocopherol [44]. Quantitative trait loci (QTL) analysis in high $\alpha$-tocopherol soybean varieties showed that polymorphism located in the $\gamma$-TMT3 promoter correlated with the higher expression of the methyl transferase, and thus that $\alpha$-tocopherol level is transcriptionally regulated in soybean seeds as well [45]. Collectively, these data demonstrate that the synthesis of $\alpha$-tocochromanols, such as $\alpha$-tocopherol in seeds and leaves, is determined by the mechanism(s) regulating the expression of the $\gamma$-TMT/VTE4 gene. To date, despite many independent research initiatives that led to the identification of numerous $\alpha$-tocopherol QTLs in Arabidopsis [46], soybean [45,47,48], maize [42,43,49,50], winter oilseed rape [51,52], and barley [53], the transcriptional machinery regulating the expression of $\gamma$-TMT genes in plants is still unknown.

\section{Plastidic Availability in Homogentisate Regulates Tocochromanol Synthesis}

Early feeding experiments of safflower, sunflower, and soybean cell cultures with HGA have shown that an exogenous HGA supply significantly increased tocochromanol biosynthesis in plant cells [54-56]. These indicate that the endogenous mechanism(s) regulating HGA biosynthesis and availability in plant cells directly determines the final amount of tocochromanols. The tocochromanol biosynthetic precursor HGA comes from the degradation of the aromatic amino acid L-tyrosine (L-tyr), which is produced by the plastidic shikimate pathway (Figure 2). L-tyr is first converted into 4-hydroxyphenylpyruvate (HPP) by tyrosine aminotransferases (TATs). Among the six to 10 TAT genes identified in the genetic model Arabidopsis, the enzymatic activity has been experimentally confirmed only for TAT1 (also named TAT7) and TAT2 [57-60]. Regarding tocochromanol synthesis, it has been shown that TAT1/TAT7 controls $35-50 \%$ of $\alpha$-tocopherol biosynthesis in Arabidopsis leaves [59]. The other TAT(s) involved in the TAT1-independent tocochromanol biosynthesis, as well as the ones involved in seed tocochromanol biosynthesis, have not been identified yet. Following tyrosine transamination, HPP is converted by 4-hydroxyphenylpyruvate dioxygenase (HPPD) into HGA 
(Figure 2). A corpus of biochemical, genetic, and cell biology data indicate that the cellular compartment hosting HGA biosynthesis is different among plant species. This aspect of tocochromanol biosynthesis has been recently reviewed in detail [17]. In the genetic model Arabidopsis, several studies have provided evidence that HGA biosynthesis is confined to the cytoplasm. The sequence analysis of the Arabidopsis TAT1/TAT7 and HPPD genes have shown that both lack the typical sequence encoding for a chloroplast transit peptide, suggesting that TAT1/AtTAT7 and HPPD are localized in the cytoplasm [60]. This has been confirmed by Western blot for HPPD, and with TAT1:GFP and HPPD:GFP fusion proteins, which were both localized in the cytoplasm of Arabidopsis cells [60,61].

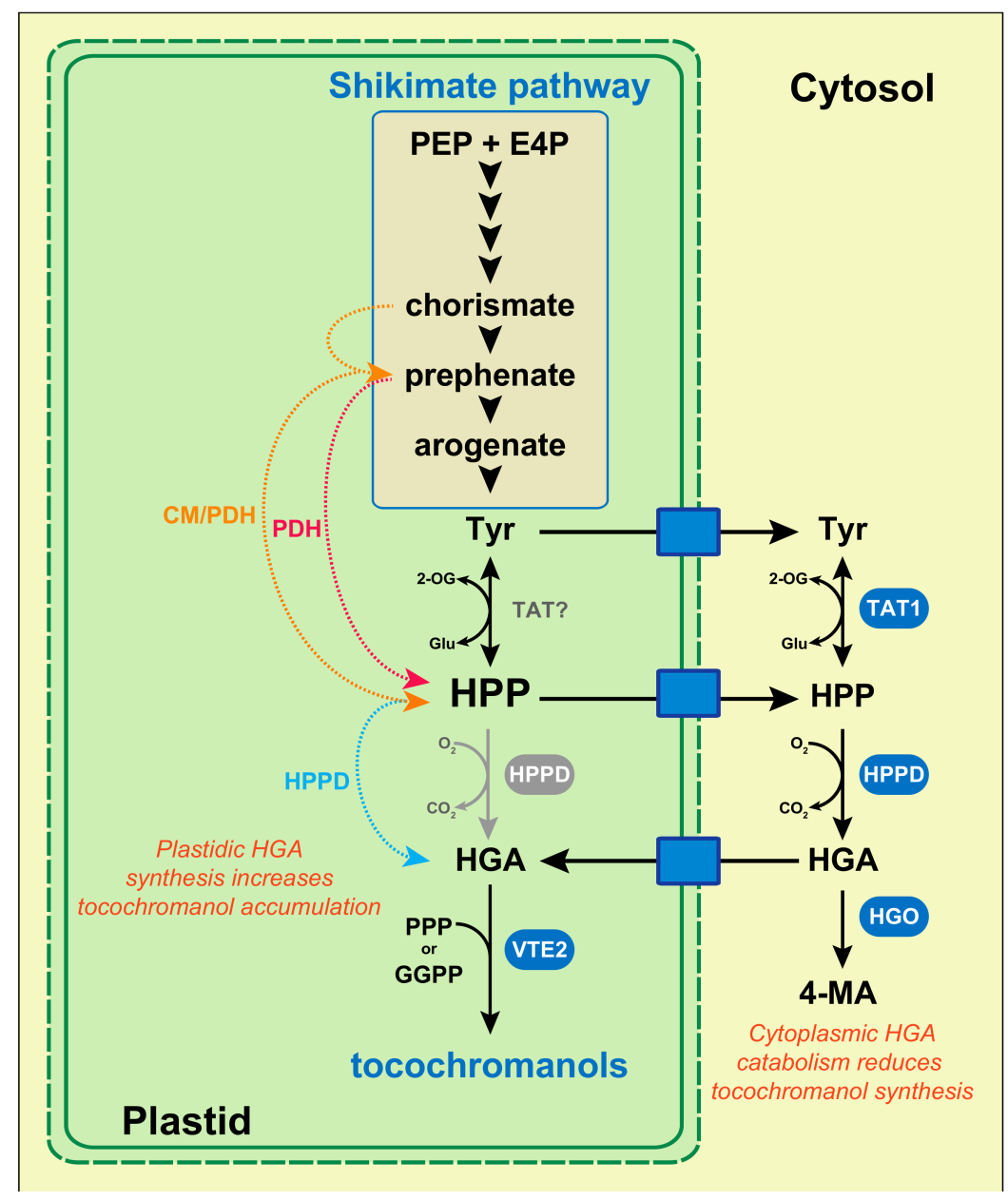

Figure 2. Biosynthesis and transport of homogentisate in plants. Red, orange, and blue dotted lines correspond to transgenic plants overexpressing the coding sequence of yeast $P D H$, bacterial $C M / P D H$, and plant $H P P D$, respectively, all fused to a sequence encoding a chloroplast transit peptide. Biosynthetic enzymes demonstrated to be involved in tocochromanol synthesis are highlighted in blue or gray. In species such as Arabidopsis, HPPD is localized in the cytoplasm. In contrast, in maize, tomato, and cotton, HPPD genes exhibit a typical chloroplast transit signal, suggesting that this enzyme is localized in the chloroplasts of these species (HPPD in grey). In soybean, HPPD have been localized in both compartments. Plant species in which HGA biosynthesis is localized in the cytosol must have chloroplast membrane transporters (blue boxes) exporting Tyr and HPP into the cytosol, and importing HGA back into chloroplasts. Abbreviations: $\mathrm{CM} / \mathrm{PDH}$, bacterial bi-functional chorismate mutase/prephenate dehydrogenase; $\mathrm{E} 4 \mathrm{P}$, erythrose 4-phosphate; GGPP, geranylgeranyl pyrophosphate; Glu, glutamate; HGA, homogentisate; HGO, homogentisate dioxygenase; HPP, 4-hydroxyphenylpyruvate; HPPD, 4-hydroxyphenylpyruvate dioxygenase; 4-MA, 4-maleylacetoacetate; 2-OG, 2-oxoglutarate; PDH, prephenate dehydrogenase; PEP, phosphoenolpyruvate; PPP, phytyl pyrophosphate; TAT, tyrosine aminotransferase; Tyr, L-tyrosine. 
In addition, HPPD genes isolated from barley, carrot, and coleus also lack chloroplast transit peptide sequences [62]. Collectively, these demonstrate that HGA biosynthesis, at least in these species, is exclusively localized in the cytoplasm. This data has major consequences regarding the regulation of tocochromanol biosynthesis in these species, since the cytoplasmic HGA biosynthesis implies the existence of chloroplast membrane transporters that export L-tyr/HPP into the cytoplasm, and other one(s) that import HGA back into chloroplasts (Figure 2). Thus, beyond HGA biosynthesis per se, these chloroplast membrane transporters might constitute additional levels of regulation of plastidic HGA availability, and thus determine the final amount of tocochromanol produced by a given tissue.

Genetic data obtained from soybean further illustrate how the cytoplasmic HGA biosynthesis and the exchanges of tocochromanol biosynthetic precursors between chloroplasts and the cytoplasm participate in the regulation of tocochromanol biosynthesis in plants. In this species, the HPPD activity is encoded by a single gene that exhibits two transcription start sites. It has been shown that the long transcript encodes a polypeptide imported into the chloroplast, while the short one encodes a polypeptide that remains in the cytoplasm [63]. This indicates that soybean HPPD activity is localized in both the cytoplasm and chloroplasts. In addition, seeds of the soybean hoo1 mutant, which carries a mutated HOMOGENTISATE DIOXYGENASE 1 gene encoding an enzyme that catabolizes HGA into 4-maleylacetoacetate (Figure 2), exhibits higher amounts of both HGA and tocochromanols [64]. Interestingly, the HGO1 activity catabolizing HGA is localized in the cytoplasm of soybean cells, indicating that the cytoplasmic HGA catabolism negatively impacts tocochromanol biosynthesis in this species. Similarly, the Arabidopsis HGO gene (At5g54080) encodes a protein expected to be localized in the cytoplasm, according to the The Arabidopsis Information Resource website. Collectively, these data demonstrate that the cytoplasmic HGA synthesis and catabolism in species such as Arabidopsis and soybean are two mechanisms that determine the final amount of tocochromanols in seeds. Moreover, they reveal that yet-unknown chloroplast membrane transporters exporting L-tyr/HPP into the cytoplasm, and other one(s) importing HGA back into chloroplasts, are potentially limiting factors for tocochromanol accumulation. To date, neither the membrane chloroplast transporters exporting L-tyr and HPP in the cytoplasm, nor the one importing HGA back into chloroplasts, have been identified in Arabidopsis. In contrast, a cationic amino acid transporter localized in the chloroplast membrane and capable of exporting phenylalanine, tryptophan, and L-tyr from the stroma into the cytosol has been identified in petunia [65].

The major role of plastidic HGA availability and its transport from the cytoplasm into plastids in the regulation of tocochromanol biosynthesis can be deduced from four metabolic engineering studies that aimed at increasing plant vitamin E activity. In higher plants, HPP derives from the sequential catabolism of L-tyr into chorismate, prephenate, and arogenate (Figure 2). In plants, L-tyr restricts its own biosynthesis, and thus the one of tocochromanols, by feedback inhibition of both arogenate dehydrogenase and prephenate dehydrogenase [20]. In contrast, prokaryotes and yeast produce HPP directly from chorismate via bi-functional chorismate mutase (CM)/prephenate dehydrogenase (PDH) activity, and from prephenate via PDH activity, respectively (Figure 2). It has been previously shown that the overexpression of bacterial $C M / P D H$ or yeast $P D H$ genes in transgenic plants, including Arabidopsis, strongly increases the accumulation of both HGA and tocochromanols $[20,56,66]$. Interestingly, both $C M / P D H$ and $P D H$ coding sequences were fused to a sequence encoding a chloroplast transit peptide and expressed in combination with HPPD genes that were also fused to a sequence encoding a chloroplast transit peptide. Collectively, these studies demonstrate that bypassing the plant L-tyr feedback inhibition and functionalizing chloroplasts with the HPPD activity significantly stimulate tocochromanol metabolism in plants.

Interestingly, the overexpression of bacterial $C M / P D H$ or yeast $P D H$ genes alone is more effective in terms of tocochromanol biosynthesis in Arabidopsis leaves than when these genes are co-expressed in combination with HPPD [20,36]. Compared with transgenic Arabidopsis overexpressing CM/PDH alone, the lower tocochromanol accumulation in transgenic Arabidopsis leaves carrying both transgenes (CM/PDH or PDH with HPPD) correlates with a much higher accumulation of free HGA [20]. This indicates that whereas HGA availability is limiting for tocochromanol accumulation, a high HGA concentration likely 
inhibits their biosyntheses. In addition to revealing the potentially toxic effect of HGA on tocochromanol metabolism, these two later studies indicate that the HPPD activity and HPP/HGA trafficking across chloroplast membranes are both not limiting in Arabidopsis leaves. Indeed, the overaccumulation of tocochromanols resulting from the sole overexpression of $C M / P D H$ or $P D H$ in chloroplasts implies that HPP is efficiently exported into the cytosol where the HPPD activity is localized, and that the cytoplasmic HGA is imported back into chloroplasts to sustain tocochromanol biosynthesis (Figure 2). Since tocochromanol biosynthesis is strongly increased by the overexpression of a bacterial CM/PDH gene alone in Arabidopsis leaves, one can conclude that the endogenous HPPD activity (cytoplasmic) and HPP/HGA trafficking are both not so limiting for leaf tocochromanol metabolism in Arabidopsis. In contrast to this, the situation seems very different in tobacco leaves; while the overexpression of the yeast $P D H$ gene does not significantly alter tocochromanol accumulation in transgenic tobacco leaves, its overexpression in combination with HPPD fused to a chloroplast targeting sequence strongly increases tocochromanol accumulation [66]. The reasons explaining these differences between Arabidopsis and tobacco leaves are currently unknown but suggest that HPPD activity and/or HPP/HGA trafficking in tobacco is limiting compared to Arabidopsis leaves.

In Arabidopsis seeds, re-analysis of previously published data indicates that HPP/HGA trafficking across the chloroplast membranes is much less efficient than in leaves despite the significant tocochromanol metabolism in this tissue. Co-expression of $C M / P D H$ in combination with HPPD in Arabidopsis stimulates seed tocochromanol accumulation, whereas the expression of $C M / P D H$ alone does not significantly alter it (construct pMON36596 versus pMON36520 in the Supplementary data of Karunanandaa et al. [56], 2005, respectively). In this study, a sequence encoding a chloroplast transit peptide was fused to both $C M / P D H$ and HPPD sequences as well, showing that seed tocochromanol might be enhanced in seeds if seed chloroplasts are functionalized with both activities. This indicates that the endogenous HPPD activity and/or HPP/HGA trafficking is much less efficient in Arabidopsis seeds than in leaves. However, the HPPD gene is strongly expressed in Arabidopsis seeds, a tissues in which HPPD expression is among its highest during plant development (Figure 3).

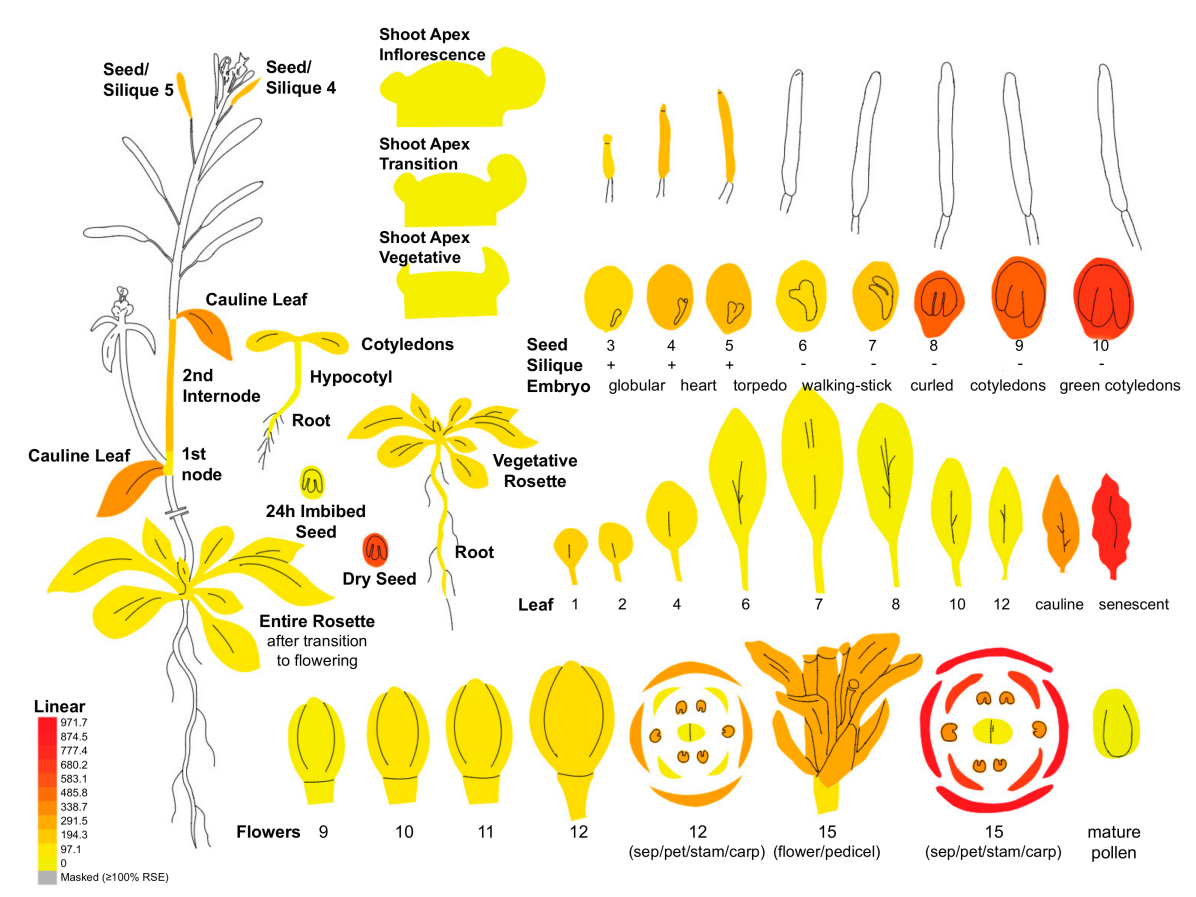

Figure 3. $H P P D$ expression pattern during Arabidopsis development. The expression of the Arabidopsis HPPD gene (At1g06570) was assessed with ePlant (http:/ / bar.utoronto.ca/eplant). HPPD expression level is equal to 697.5 in green cotyledons ( $\mathrm{SD}=36.3 ; n=3)$, and is the third highest HPPD expression after sepals (level $=971.7 ; \mathrm{SD}=84.2 ; n=3$ ) and senescent leaves (level $=797.7 ; \mathrm{SD}=6.9 ; n=3$ ). 
This indicates that HPPD activity is likely not limiting tocochromanol metabolism in Arabidopsis seeds, and that in contrast, HPP/HGA trafficking restricts tocochromanol biosynthesis in these tissues. This novel interpretation of old data also suggests that HPP/HGA trafficking across the chloroplast membrane is likely a target of choice to increase tocochromanol biosynthesis in seeds.

The tocochromanol patterns of transgenic plants expressing bacterial $C M / P D H$ and yeast $P D H$ alone or in combination with HPPD vary according to the plant species, organ, and developmental stage. Thus, while young tobacco and Arabidopsis leaves overexpressing $C M / P D H$ or $P D H$ genes overaccumulate primarily tocotrienols, mature Arabidopsis transgenic leaves expressing these constructs accumulate mostly tocopherols $[20,36,66]$. In contrast to leaves, Arabidopsis and soybean transgenic seeds expressing CM/PDH or $P D H$ genes primarily overaccumulate tocotrienols [56]. Since the type of tocochromanol results from the polyprenyl pyrophosphate substrate, these results indicate that the tocopherol precursor PPP is likely limiting in seeds and young leaf tissues, whereas GGPP is not.

\section{Regulation of Polyprenyl Pyrophosphate Availability}

Since the type of tocochromanol (tocopherol, tocotrienol, PC-8, tocomonoenol) is determined by the polyprenyl pyrophosphate substrate condensed to HGA, the biosynthetic pathways producing the lipophilic tocochromanol precursors (PPP, GGPP, SPP, and THGGPP) are key components in the regulation of tocochromanol biosynthesis. To date, although the tocotrienol biosynthetic pathway is well characterized, and key tocotrienol biosynthetic genes have been identified in plants, there are currently no data describing the mechanisms regulating the biosynthesis of GGPP used for tocotrienol biosynthesis [32]. This may result from the fact that the wild accessions of the genetic model Arabidopsis do not accumulate the tocotrienols that are mostly prevalent in the seeds of Poaceae. As the GGPP that is used for tocotrienol synthesis likely originates from the plastidic methyl erythritol phosphate pathway (MEP), one can assume that the regulation of tocotrienol biosynthesis might be directly linked to this pathway. In addition, the mapping of the tocotrienol QTLs identified in maize and barley grains might improve our understanding of the mechanisms regulating its accumulation $[67,68]$. It is known that tocotrienols accumulate in plants or tissues that do not usually produce them when HGA is overaccumulated, such as in transgenic Arabidopsis plants expressing CM/PDH or PDH genes, or in the leaves of transgenic tobacco carrying similar constructs $[20,36,56,66]$. The current interpretation of these data is that GGPP is likely not limiting in these species or tissues, and that HGA overaccumulation alters the specificity of the tocopherol prenyltransferase. These results might indicate that HGA availability in Poaceae seeds might contribute to the regulation of tocotrienol biosynthesis in these species.

The biosynthesis of PC-8 and its solanesyl benzoquinone precursor plastoquinone-9 (PQ-9) is initiated by the homogentisate solanesyltransferase-dependent condensation of HGA with SPP that comes from the preferential concatenation of GGPP and isopentenyl pyrophosphate [25,69-71]. To date, four genes have been found to specifically regulate PQ-9/PC-8 accumulation in plants. The Nicotinamide Adenine Dinucleotide Phosphate (NADPH) dehydrogenase C1 (NDC1; AT5G08740) is a type II $\mathrm{NAD}(\mathrm{P}) \mathrm{H}$ quinone oxidoreductase that reduces $\mathrm{PQ}-9$ into $\mathrm{PQH}_{2}-9$, using ferredoxin as an electron donor [72]. This enzyme is localized in plastoglobuli together with prenyl quinones/quinols and tocochromanols such as PC-8. In Arabidopsis $n d c 1$ mutants, the leaf PQ pool is more oxidized than in wild-type controls, while PC-8 amounts are reduced by ca $66 \%$ [72]. In contrast, leaf tocopherol levels were not affected by the mutation. The proposed model explaining the role of NDC1 in PC-8 accumulation is based on tocopherol cyclase-the enzyme that notably catalyzes the cyclization of $\mathrm{PQH}_{2}-9$ into $\mathrm{PC}-8$ - preferentially using reduced prenyl quinones [73]. Two $\mathrm{ABC} 1$ atypical kinases, ABC1K1 (AT4G31390) and K3 (AT1G79600), have been shown to regulate PQ-9/PC-8 metabolism in Arabidopsis [74-76]. Both kinases are abundant in plastoglobuli, and single and double $a b c 1 k 1$ and $a b c 1 k 3$ mutants exhibit altered PQ-9/PC-8 metabolism. Although the function of these atypical kinases in PQ-9/PC-8 metabolism has been clearly demonstrated, their mode(s) of action remains to be determined. It has been shown that both $\mathrm{ABC} 1 \mathrm{~K} 1$ and $\mathrm{K} 3$ phosphorylate the tocopherol cyclase VTE1. 
Since the biosynthesis of tocopherols, which requires VTE1 activity as well, was not affected in $a b c 1 k 3$ leaves, it is unlikely that the ABC1K3 mode of action is mediated by VTE1 phosphorylation. In contrast, tocopherol amounts were significantly reduced in $a b c 1 k 1$ leaves, suggesting that the ABC1K1 mode of action might involve the regulation of the tocopherol cyclase activity. The role of ABC1K1 and $\mathrm{K} 3$ in tocochromanol metabolism might also be mediated by the synthesis of fribrillin, a group of lipid-associated proteins that are localized in chloroplasts and essential for the biosynthesis of PQ-9, and thus PC-8 [77,78]. Indeed, Arabidopsis fibrillin-5 mutants exhibit lower PQ-9/PC-8 amounts, and it was shown that mutation in $a b c 1 k 3$ strongly reduces the accumulation of fibrillin proteins [74,77].

Regarding the regulation of tocopherol biosynthesis, it is known that the availability of phytol is a major parameter governing the final amount of tocopherols in a plant tissue. It has been shown, for instance, that the supplementation of plant cell suspensions with free phytol is sufficient to significantly increase tocopherol accumulation in these cells [54-56]. Moreover, feeding Arabidopsis seedlings with radiolabeled phytol has been associated with the biosynthesis of radiolabeled $\alpha$-tocopherol, thus suggesting that free phytol is likely recycled into tocopherols [79]. The first genetic evidence supporting this biosynthetic model was provided by the Arabidopsis vte 5 that lacks $80 \%$ and $65 \%$ of the tocopherols in seeds and leaves, respectively [80]. Recently, the VTE5-dependent biosynthesis of tocopherols has also been reported in tomato leaves and fruits [81]. VTE5 is a phytol kinase that phosphorylates the free phytol that is released during chlorophyll catabolism into phytyl phosphate [80]. The chlorophyll-dependent tocopherol biosynthesis is further supported by genetic data provided by the Arabidopsis $g 4 / c h l s y n 1$ mutant, which carries a mutated chlorophyll synthase that esterifies geranylgeranyl pyrophosphate on chlorophyllide $a$ [82]. The leaves of this mutant grown in vitro on a media supplemented with sucrose are albino, and do not accumulate tocopherols. In addition, $g 4 /$ chlsyn 1 seeds lack $75 \%$ of the tocopherols, thus indicating that tocopherol biosynthesis is also mostly chlorophyll-dependent in Arabidopsis seeds as well. Collectively, these data demonstrate that the PPP used for tocopherol biosynthesis primarily originates from the recycling of phytol released during chlorophyll catabolism in both leaves and seeds. This biosynthetic model, including details about enzymes such as Mg-dechelatase, chlorophyllases, and pheophytinase, has been very recently reviewed, and will not be developed here [17].

If one can easily understand the origin of PPP in the seeds of chloroembryophytes such Arabidopsis or rapeseed, which accumulate significant amounts of chlorophylls in developing embryos, how do leucoembryophyte seeds produce tocopherols, since they a priori do not synthetize chlorophylls? A comprehensive analysis of vitamin E natural variation in maize grain recently provided an unexpected answer to this puzzling question. Among the 52 QTLs identified for maize grain tocochromanols, QTL5 and QTL24 exhibited scores for phenotypic variance explained among the highest of all identified QTLs [68]. Interestingly, DNA loci covered by QTL5 andQTL24 both carry a gene encoding protochlorophyllide reductase, an enzyme of the chlorophyll biosynthetic pathway [68]. This result suggests that despite their lack of green coloration, leucoembryophyte seeds such as maize grain might produce chlorophylls that, once degraded and recycled, might provide PPP for tocopherol biosynthesis. A biochemical analysis of developing maize grain showed that, whereas they lack any macroscopic green coloration, embryos accumulate very low but detectable traces of the chlorophyll immediate precursor chlorophyllide $a$, of chlorophylls $a$ and $b$, and of the first chlorophyll catabolite that lacks the Mg atom pheophytin $a$. In addition, endosperm also accumulated detectable traces of chlorophyll $a$. Although further studies-notably with genetic evidence-are required to definitively link chlorophyll metabolism and tocopherol biosynthesis in leucoembryophyte seeds, these data indicate that leucoembryophyte seeds might produce tocopherols via the same mechanism originally described in chloroembryophyte seeds $[80,83]$. This exiting perspective would definitively link tocopherol metabolism to the one of chlorophylls in plants, and open news questions regarding tocopherol metabolism in non-photosynthetic organisms such as in Plasmodium falciparum [14-16].

Although the chlorophyllic origin of tocopherols is clearly established in the seeds and leaves of chloroembryophyte species such as Arabidopsis, little is known about the regulation 
of PPP biosynthesis linked to tocopherol accumulation. Recently, two novel Arabidopsis ethane methylsulfonate mutants, the enhanced vitamin $e$ (eve) 1 and 4 mutants, have been isolated by forward genetics [21]. The seeds of eve1 and eve4 mutants overaccumulate tocopherols, PC-8, and $\gamma$-tocomonoenol, a monounsaturated form of tocochromanols. Interestingly, both eve1 and 4 seeds did not accumulate any tocotrienols, such as transgenic Arabidopsis plants overaccumulating HGA, suggesting that although HGA metabolism is likely increased in these mutants to sustain tocochromanol metabolism, HGA overaccumulation is not the primary source of its enhancement. In addition, $\gamma$-tocomonoenol accumulation has never been reported in Arabidopsis HGA overaccumulating lines, further suggesting that the misregulation of HGA biosynthesis is likely not the primary source of the enhancement of tocochromanol accumulation in eve1 and eve4 seeds. The fact that all tocochromanol forms are overaccumulated in eve1 and eve4 seeds likely suggests that both mutations affect the chloroplastic isoprenoid metabolism produced by the methyl erythritol phosphate pathway (Figure 4). The mutation responsible for the eve1 seed phenotype affects the WRINKLED1 gene that encodes for a transcription factor containing two APETALA2/ethylene response element DNA-binding proteins [84]. This gene is mostly expressed during seed development, although moderate expression has been also detected in roots and flowers $[85,86]$.

\section{GLYCOLYSIS}

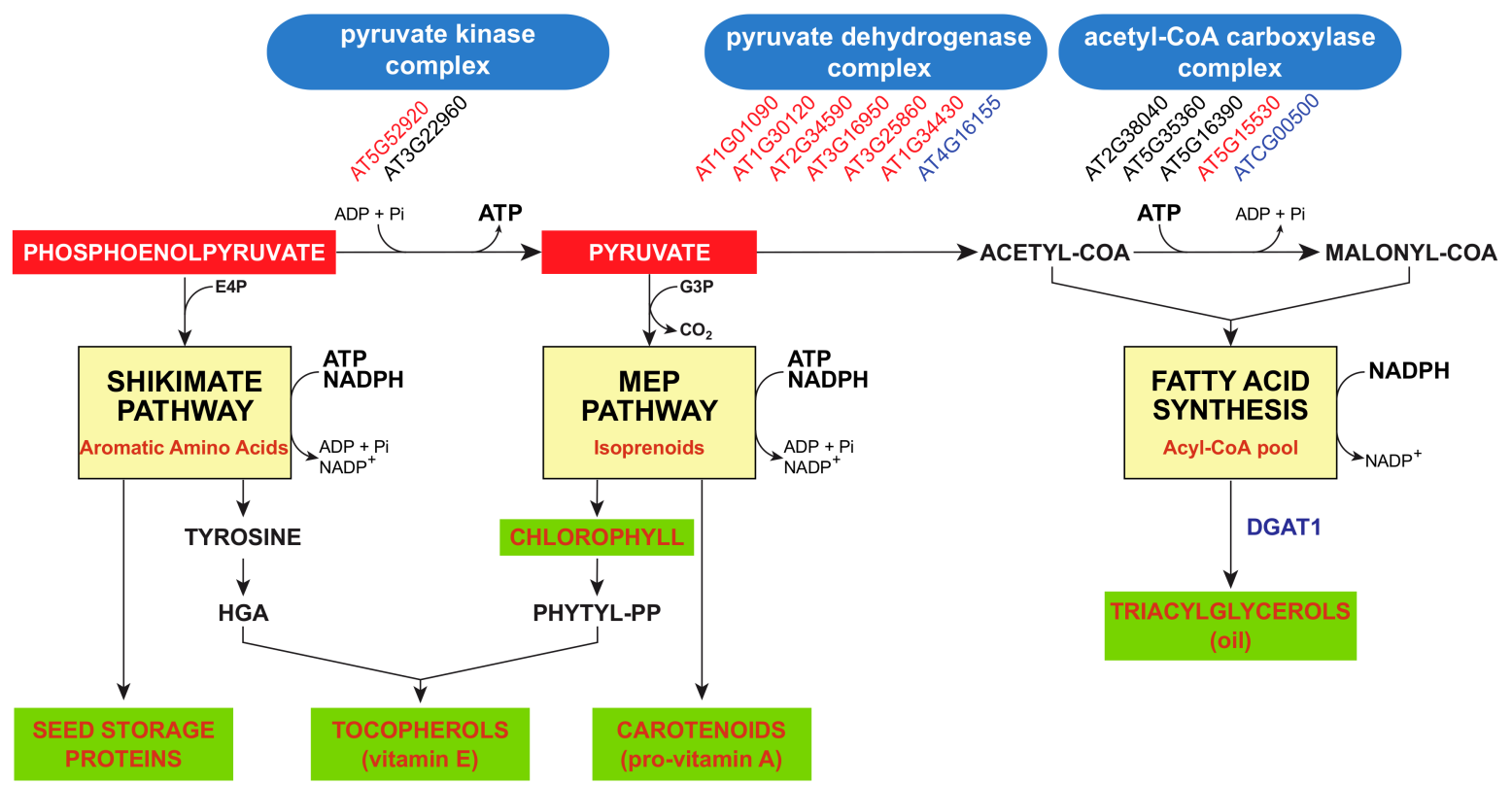

Figure 4. Plastidic intersection of the shikimate pathway, the methyl erythritol phosphate pathway, and lipogenesis. The shikimate pathway, methyl erythritol phosphate (MEP) pathway, and fatty acid synthesis are localized in plastids, and share phosphoenolpyruvate and pyruvate as common biosynthetic precursors. The biosynthesis of triacylglycerols occurs in the endoplasmic reticulum. Arabidopsis Genome Initiative numbers in red indicate that the corresponding gene is downregulated in Arabidopsis wri1 developing embryos, or upregulated in transgenic plants constitutively expressing the WRI1 transcription factor. AGI numbers in black indicate that the expression of the corresponding gene is WRI1-independent. AGI numbers in blue indicate that no transcriptomic data was available. Abbreviations: DGAT1, acylCoA:diacylglycerol acyltransferase 1; E4P, erythrose 4-phosphate; G3P, glyceraldehyde 3-phosphate; phytyl-PP, phytyl pyrophosphate.

Targets of the WRI1 transcription factor in plant genomes have been investigated by transcriptomic studies and in vitro enzymatic assays in developing Arabidopsis wri1 embryos [85-88], in the leaves 
of transgenic maize lines overexpressing the ZmWRI1a gene [89], and in Nicotiana benthamiana leaves agroinfiltrated with Arabidopsis, potato, poplar, oat, and nutsedge WRI1 orthologs [90]. The transcription factor WRI1 regulates the expression of several key biosynthetic genes involved in late glycolysis, fatty acid synthesis, and lipid assembly [85-89]. Thus, WRI1 pushes carbon into fatty acid/lipid metabolism by upregulating key lipid biosynthetic genes. It is interesting to note that the genes encoding almost all of the subunits of the plastidial pyruvate dehydrogenase complex are either downregulated in wri1 developing embryos or upregulated in transgenic plants overexpressing WRI1 (Figure 4). Interestingly, tocochromanols are synthetized in chloroplasts as well, and the biosynthetic pathways providing both tocochromanol precursors, i.e., the MEP pathway and the shikimate pathway, use the same biosynthetic precursors, i.e., pyruvate and phosphoenolpyruvate, as those used for fatty acid/lipid synthesis (Figure 4). These suggest that tocochromanol and lipid biosyntheses might compete for these biosynthetic precursors.

Another model explaining the enhancement of tocochromanol metabolism in wri1 seeds might be considered as well. The transient WRI1 expression performed in Nicotiana benthamiana leaves revealed a novel aspect of WRI1 transcriptome that has not been described neither in transgenic lines constitutively expressing WRI1 nor in wri1 seeds. Numerous genes encoding chlorophyll biosynthetic enzymes such as protochlorophyllide oxidoreductase and $\mathrm{Mg}$ chelatase, chlorophyll-binding proteins, subunits of the light harvesting complexes, and ATP generation complex subunits were strongly downregulated in tobacco leaves transiently expressing WRI1 constructs (Supplementary file 6 of Grimberg et al. [90]). The authors concluded that the transient expression of WRI1 is strongly associated with the downregulation of photosynthesis, including energy and reducing equivalent production, respectively. Interestingly, the endogenous WRI1 gene is not constitutively expressed in Arabidopsis plants; instead, it is transiently expressed in the developing Arabidopsis embryo [85]. This indicates that the WRI1 expression in the developing Arabidopsis embryo also might downregulate photosynthesis, and thus the production of ATP, as well as reduce equivalents in embryos. Now, the MEP pathway that produces the building blocks for chloroplastic isoprenoids is strongly dependent on ATP and reducing equivalents such as NADPH (Figure 4). Interestingly, it has been suggested that both ATP and NADPH might be key regulatory components of the MEP pathway [91]. This hypothesis suggests that the enhancement of the tocochromanol metabolism in wril seeds might reflect the higher ATP and NADPH production resulting from the reduced repression of seed photosynthesis.

\section{Conclusions and Perspectives}

From the first purification of $\alpha$-tocopherol from wheat germ oil to the latest model of the tocochromanol biosynthetic pathways introducing tocomonoenol biosynthetic genes, our understanding of vitamin $\mathrm{E}$ biosynthesis in plants has been considerably enriched $[3,21]$. In contrast, much less is known about the mechanisms regulating vitamin $\mathrm{E}$ biosynthesis in plants. The fact that tocochromanol biosynthesis mobilizes two distinct biosynthetic pathways, the shikimate pathway and the MEP pathway, requires the degradation of two compounds such as L-tyr and chlorophylls, involves a yet-unknown transport system between the cytoplasm and the stroma in plant species in which HGA biosynthesis is localized in the cytoplasm, and is interconnected to fatty acid biosynthesis in plastids, render the understanding of its regulation particularly challenging. Indeed, understanding the regulation of vitamin E biosynthesis will imply that we take up the challenges to understand the regulation of each of these numerous events. Beyond understanding the regulation of vitamin E biosynthesis in plants, it seems important that medical scientists assess the sanitary consequences of the significant vitamin E deficiency independently detected in human populations, including in developed countries. The fundamental role of this vitamin in human reproduction and its benefit in current widespread diseases such as high cholesterol and neurodegenerative pathologies makes it a candidate of choice to improve human health. 
Acknowledgments: I am grateful to the University of Fribourg and to the Foundation of Research in Biochemistry and on Vitamins (Epalinges, Switzerland) represented by Claude Bron for supporting the research developed in my laboratory.

Conflicts of Interest: The author declares no conflict of interest.

\section{References}

1. Mène-Saffrané, L.; Pellaud, S. Current strategies for vitamin E biofortification of crops. Curr. Opin. Biotechnol. 2017, 44, 189-197. [CrossRef] [PubMed]

2. Evans, H.M.; Bishop, K.S. On the existence of a hitherto unrecognized dietary factor essential for reproduction. Science 1922, 56, 650-651. [CrossRef] [PubMed]

3. Evans, H.M.; Emerson, O.H.; Emerson, G.A. The isolation from wheat germ oil of an alcohol, $\alpha$-tocopherol, having the properties of vitamin E. J. Biol. Chem. 1936, 113, 319-332. [CrossRef]

4. Galli, F.; Azzi, A.; Birringer, M.; Cook-Mills, J.M.; Eggersdorfer, M.; Frank, J.; Cruciani, G.; Lorkowski, S.; Katar Özer, N. Vitamin E: Emerging aspects and new directions. Free Radic. Biol. Med. 2017, 16-36. [CrossRef] [PubMed]

5. Li, G.X.; Lee, M.J.; Liu, A.B.; Yang, Z.; Lin, Y.; Shih, W.J.; Yang, C.S. $\delta$-tocopherol is more active than $\alpha-$ or $\gamma$-tocopherol in inhibiting lung tumorigenesis in vivo. Cancer Prev. Res. 2011, 4, 404-413. [CrossRef] [PubMed]

6. La Fata, G.; Weber, P.; Mohajeri, M.H. Effects of vitamin E on cognitive performance during ageing and in Alzheimer's disease. Nutrients 2014, 6, 5453-5472. [CrossRef] [PubMed]

7. Qureshi, A.A.; Burger, W.C.; Peterson, D.M.; Elson, C.E. The structure of an inhibitor of cholesterol biosynthesis isolated from barley. J. Biol. Chem. 1986, 261, 10544-10550. [PubMed]

8. Qureshi, A.A.; Sami, S.A.; Salser, W.A.; Khan, F.A. Dose-dependent suppression of serum cholesterol by tocotrienol-rich fraction (TRF25) of rice bran in hypercholesterolemic humans. Atherosclerosis 2002, 161, 199-207. [CrossRef]

9. Maras, J.E.; Bermudez, O.I.; Qiao, N.; Bakun, P.J.; Boody-Alter, E.L.; Tucker, K.L. Intake of $\alpha$-tocopherol is limited among US adults. J. Am. Diet. Assoc. 2004, 104, 567-575. [CrossRef] [PubMed]

10. Polito, A.; Intorre, F.; Andriollo-Sanchez, M.; Azzini, E.; Raguzzini, A.; Meunier, N.; Ducros, V.; O'Connor, J.M.; Coudray, C.; Roussel, A.M.; et al. Estimation of intake and status of vitamin A, vitamin E and folate in older European adults: The ZENITH. Eur. J. Clin. Nutr. 2005, 59, S42-S47. [CrossRef] [PubMed]

11. Kim, Y.N.; Cho, Y.O. Vitamin E status of 20- to 59-year-old adults living in the Seoul metropolitan area of South Korea. Nutr. Res. Pract. 2015, 9, 192-198. [CrossRef] [PubMed]

12. Shamim, A.A.; Schulze, K.; Merrill, R.D.; Kabir, A.; Christian, P.; Shaikh, S.; Wu, L.; Ali, H.; Labrique, A.B.; Mehra, S.; et al. Tocopherols are associated with risk of miscarriage in rural Bangladesh. Am. J. Clin. Nutr. 2015, 101, 294-301. [CrossRef] [PubMed]

13. Péter, S.; Friedel, A.; Roos, F.F.; Wyss, A.; Eggersdorfer, M.; Hoffmann, K.; Weber, P. A Systematic review of global alpha-tocopherol status as assessed by nutritional intake levels and blood serum concentrations. Int. J. Vitam. Nutr. Res. 2016, 1-21. [CrossRef] [PubMed]

14. Sussmann, R.A.C.; Angeli, C.B.; Peres, V.J.; Kimura, E.A.; Katzin, A.M. Intraerythrocytic stages of Plasmodium falciparum biosynthesize vitamin E. FEBS Lett. 2011, 585, 3985-3991. [CrossRef] [PubMed]

15. Sussman, R.A.C.; Fotoran, W.L.; Kimura, E.A.; Katzin, A.M. Plasmodium falciparum uses vitamin E to avoid oxidative stress. Parasit. Vectors 2017, 10, 461. [CrossRef] [PubMed]

16. Cassera, M.B.; Gozzo, F.C.; D’Alexandri, F.L.; Merino, E.F.; del Portillo, H.A.; Peres, V.J.; Almeida, I.C.; Eberlin, M.N.; Wunderlich, G.; Wiesner, J.; et al. The methylerythritol phosphate pathway is functionally active in all intraerythrocytic stages of Plasmodium falciparum. J. Biol. Chem. 2004, 279, 51749-51759. [CrossRef] [PubMed]

17. Pellaud, S.; Mène-Saffrané, L. Metabolic origins and transport of vitamin E biosynthetic precursors. Front. Plant Sci. 2017, 8, 1959. [CrossRef] [PubMed]

18. Collakova, E.; DellaPenna, D. Isolation and functional analysis of homogentisate phytyltransferase from Synechocystis sp. PCC 6803 and Arabidopsis. Plant Physiol. 2001, 127, 1113-1124. [CrossRef] [PubMed] 
19. Savidge, B.; Weiss, J.D.; Wong, Y-H.H.; Lassner, M.W.; Mitky, T.A.; Shewmaker, C.K.; Post-Beittenmiller, D.; Valentin, H.E. Isolation and characterization of homogentisate phytyltransferase genes from Synechocystis sp. PCC 6803 and Arabidopsis. Plant Physiol. 2002, 129, 321-332. [CrossRef] [PubMed]

20. Zhang, C.; Cahoon, R.E.; Hunter, S.C.; Chen, M.; Han, J.; Cahoon, E.B. Genetic and biochemical basis for alternative routes of tocotrienol biosynthesis for enhanced vitamin $\mathrm{E}$ antioxidant production. Plant J. 2013, 73, 628-639. [CrossRef] [PubMed]

21. Pellaud, S.; Bory, A.; Chabert, V.; Romanens, J.; Chaisse-Leal, L.; Doan, A.V.; Frey, L.; Gust, A.; Fromm, K.M.; Mène-Saffrané, L. WRINKLED1 and ACYL-COA:DIACYLGLYCEROL ACYLTRANSFERASE1 regulate tocochromanol metabolism in Arabidopsis. New Phytol. 2018, 217, 1-16. [CrossRef] [PubMed]

22. Yang, W.; Cahoon, R.E.; Hunter, S.C.; Zhang, C.; Han, J.; Borgschulte, T.; Cahoon, E.B. Vitamin E biosynthesis: Functional characterization of the monocot homogentisate geranylgeranyl transferase. Plant J. 2011, 65, 206-217. [CrossRef] [PubMed]

23. Mène-Saffrané, L.; Jones, A.D.; DellaPenna, D. Plastochromanol-8 and tocopherols are essential lipid-soluble antioxidants during seed desiccation and quiescence in Arabidopsis. Proc. Natl. Acad. Sci. USA 2010, 107, 17815-17820. [CrossRef] [PubMed]

24. Sadre, R.; Gruber, J.; Frentzen, M. Characterization of homogentisate prenyltransferases involved in plastoquinone-9 and tocochromanol biosynthesis. FEBS Lett. 2006, 580, 5357-5362. [CrossRef] [PubMed]

25. Tian, L.; DellaPenna, D.; Dixon, R.A. The pds2 mutation is a lesion in the Arabidopsis homogentisate solanesyltransferase gene involved in plastoquinone biosynthesis. Planta 2007, 226, 1067-1073. [CrossRef] [PubMed]

26. Cheng, Z.; Sattler, S.; Maeda, H.; Sakuragi, Y.; Bryant, D.A.; DellaPenna, D. Highly divergent methyltransferases catalyze a conserved reaction in tocopherol and plastoquinone synthesis in Cyanobacteria and photosynthetic Eukaryotes. Plant Cell 2003, 15, 2343-2356. [CrossRef] [PubMed]

27. Van Eenennaam, A.L.; Lincoln, K.; Durrett, T.P.; Valentin, H.E.; Shewmaker, C.K.; Thorne, G.M.; Jiang, J.; Baszis, S.R.; Levering, C.K.; Aasen, E.D.; et al. Engineering vitamin E content: From Arabidopsis mutant to soy oil. Plant Cell 2003, 15, 3007-3019. [CrossRef] [PubMed]

28. Porfirova, S.; Bergmüller, E.; Tropf, S.; Lemke, R.; Dörmann, P. Isolation of an Arabidopsis mutant lacking vitamin $\mathrm{E}$ and identification of a cyclase essential for all tocopherol biosynthesis. Proc. Natl. Acad. Sci. USA 2002, 99, 12495-12500. [CrossRef] [PubMed]

29. Sattler, S.E.; Gilliland, L.U.; Magallanes-Lundback, M.; Pollard, M.; DellaPenna, D. Vitamin E is essential for seed longevity and for preventing lipid peroxidation during germination. Plant Cell 2004, 16, 1419-1432. [CrossRef] [PubMed]

30. Shintani, D.; DellaPenna, D. Elevating the vitamin E content of plants through metabolic engineering. Science 1998, 282, 2098-2100. [CrossRef] [PubMed]

31. Bergmüller, E.; Porfirova, S.; Dörmann, P. Characterization of an Arabidopsis mutant deficient in $\gamma$-tocopherol methyltransferase. Plant Mol. Biol. 2003, 52, 1181-1190. [CrossRef] [PubMed]

32. Cahoon, E.B.; Hall, S.E.; Ripp, K.G.; Ganzke, T.S.; Hitz, W.D.; Coughlan, S.J. Metabolic redesign of vitamin E biosynthesis in plants for tocotrienol production and increased antioxidant content. Nat. Biotechnol. 2003, 21, 1082-1087. [CrossRef] [PubMed]

33. Hosomi, A.; Arita, M.; Sato, Y.; Kiyose, C.; Ueda, T.; Igarashi, O.; Arai, H.; Inoue, K. Affinity of alpha-tocopherol transfer protein as a determinant of the biological activities of vitamin E analogs. FEBS Lett. 1997, 409, 105-108. [CrossRef]

34. Aeschimann, W.; Staats, S.; Kammer, S.; Olieric, N.; Jeckelmann, J.M.; Fotiadis, D.; Netscher, T.; Rimbach, G.; Cascella, M.; Stocker, A. Self-assembled $\alpha$-tocopherol transfer protein nanoparticles promote vitamin $\mathrm{E}$ delivery across an endothelial barrier. Sci. Rep. 2017, 7, 4970. [CrossRef] [PubMed]

35. Zbierzak, A.M.; Kanwischer, M.; Wille, C.; Vidi, P.A.; Giavalisco, P.; Lohmann, A.; Briesen, I.; Porfirova, S.; Bréhélin, C.; Kessler, F.; et al. Intersection of the tocopherol and plastoquinol metabolic pathways at the plastoglobule. Biochem. J. 2010, 425, 389-399. [CrossRef] [PubMed]

36. Tzin, V.; Malitsky, S.; Aharoni, A.; Galili, G. Expression of a bacterial bi-functional chorismate mutase/prephenate dehydratase modulates primary and secondary metabolism associated with aromatic amino acids in Arabidopsis. Plant J. 2009, 60, 156-167. [CrossRef] [PubMed] 
37. Jiang, J.; Jia, H.; Feng, G.; Wang, Z.; Li, J.; Gao, H.; Wang, X. Overexpression of Medicago sativa TMT elevates the $\alpha$-tocopherol content in Arabidopsis seeds, alfalfa leaves, and delays dark-induced leaf senescence. Plant Sci. 2016, 249, 93-104. [CrossRef] [PubMed]

38. Endrigkeit, J.; Wang, X.; Cai, D.; Zhang, C.; Long, Y.; Meng, J.; Jung, C. Genetic mapping, cloning, and functional characterization of the BnaX.VTE4 gene encoding a $\gamma$-tocopherol methyltransferase from oilseed rape. Theor. Appl. Genet. 2009, 119, 567-575. [CrossRef] [PubMed]

39. Tang, S.; Hass, C.G.; Knapp, S.J. Ty3/gypsy-like retrotransposon knockout of a 2-methyl-6-phytyl-1,4benzoquinone methyltransferase is non-lethal, uncovers a cryptic paralogous mutation, and produces novel tocopherol (vitamin E) profiles in sunflower. Theor. Appl. Genet. 2006, 113, 783-799. [CrossRef] [PubMed]

40. Lampi, A.M.; Nurmi, T.; Ollilainen, V.; Piironen, V. Tocopherols and tocotrienols in wheat genotypes in the HEALGRAIN diversity screen. J. Agric. Food Chem. 2008, 56, 9716-9721. [CrossRef] [PubMed]

41. Goffman, F.D.; Velasco, L.; Thies, W. Quantitative determination of tocopherols in single seeds of rapeseed (Brassica napus L.). Lipid 1999, 101, 142-145. [CrossRef]

42. Xu, S.T.; Zhang, D.L.; Cai, Y.; Zhou, Y.; Shah, T.; Ali, F.; Li, Q.; Li, Z.G.; Wang, W.D.; Li, J.S.; et al. Dissecting tocopherols content in maize (Zea mays L.), using two segregating populations and high-density single nucleotide polymorphism markers. BMC Plant Biol. 2012, 12, 201-214. [CrossRef]

43. Lipka, A.E.; Gore, M.A.; Magallanes-Lundback, M.; Mesberg, A.; Lin, H.; Tiede, T.; Chen, C.; Buell, C.R.; Buckler, E.S.; Rocheford, T.; et al. Genome-wide association study and pathway-level analysis of tocochromanol levels in maize grain. G3 (Bethesda) 2013, 3, 1287-1299. [CrossRef] [PubMed]

44. Ujiie, A.; Yamada, T.; Fujimoto, K.; Endo, Y.; Kitamura, K. Identification of soybean varieties with high $\alpha$-tocopherol content. Breed. Sci. 2005, 55, 123-125. [CrossRef]

45. Dwiyanti, M.S.; Yamada, T.; Sato, M.; Abe, J.; Kitamura, K. Genetic variation of $\gamma$-tocopherol methyltransferase gene contributes to elevated $\alpha$-tocopherol content in soybean seeds. BMC Plant Biol. 2011, 11, 152-168. [CrossRef] [PubMed]

46. Gilliland, L.U.; Magallanes-Lundback, M.; Hemming, C.; Supplee, A.; Koornneef, M.; Bentsink, L.; DellaPenna, D. Genetic basis for natural variation in seed vitamin E levels in Arabidopsis thaliana. Proc. Natl. Acad. Sci. USA 2006, 103, 18834-18841. [CrossRef] [PubMed]

47. Li, H.; Wang, Y.; Han, Y.; Teng, W.; Zhao, X.; Li, Y.; Li, W. Mapping quantitative trait loci (QTLs) underlying seed vitamin E content in soybean with main, epistatic and QTL $\times$ environment effects. Plant Breed. 2016, 135, 208-214. [CrossRef]

48. Shaw, E.J.; Rajcan, I. Molecular mapping of soybean seed tocopherols in the cross 'OAC Bayfield' $\times$ 'OAC Shire'. Plant Breed. 2017, 136, 83-93. [CrossRef]

49. Chander, S.; Guo, Y.Q.; Yang, X.H.; Yan, J.B.; Zhang, Y.R.; Song, T.M.; Li, J.S. Genetic dissection of tocopherol content and composition in maize grain using quantitative trait loci analysis and the candidate gene approach. Mol. Breed. 2008, 22, 353-365. [CrossRef]

50. Li, Q.; Yang, X.; Xu, S.; Cai, Y.; Zhang, D.; Han, Y.; Li, L.; Zhang, Z.; Gao, S.; Li, J.; et al. Genome-wide association studies identified three independent polymorphisms associated with $\alpha$-tocopherol content in maize kernels. PLoS ONE 2012, 7, e36807. [CrossRef] [PubMed]

51. Marwede, V.; Gül, M.K.; Becker, H.C.; Ecke, W. Mapping of QTL controlling tocopherol content in winter oilseed rape. Plant Breed. 2005, 124, 20-26. [CrossRef]

52. Wang, X.; Zhang, C.; Li, L.; Fritsche, S.; Endrigkeit, J.; Zhang, W.; Long, Y.; Jung, C.; Meng, J. Unraveling the genetic basis of seed tocopherol content and composition in rapeseed (Brassica napus L.). PLoS ONE 2012, 7, e50038. [CrossRef] [PubMed]

53. Oliver, R.E.; Islamovic, E.; Obert, D.E.; Wise, M.L.; Herrin, L.L.; Hang, A.; Harrison, S.A.; Ibrahim, A.; Marshall, J.M.; Miclaus, K.J.; et al. Comparative systems biology reveals allelic variation modulating tocochromanol profiles in barley (Hordeum vulgare L.). PLoS ONE 2014, 9, e96276. [CrossRef] [PubMed]

54. Furuya, T.; Yoshikawa, T.; Kimura, T.; Kaneko, H. Production of tocopherols by cell culture of safflower. Phytochemistry 1987, 26, 2741-2747. [CrossRef]

55. Caretto, S.; Speth, E.B.; Fachechi, C.; Gala, R.; Zacheo, G.; Giovinazzo, G. Enhancement of vitamin E production in sunflower cell cultures. Plant Cell Rep. 2004, 23, 174-179. [CrossRef] [PubMed] 
56. Karunanandaa, B.; Qi, Q.; Hao, M.; Baszis, S.R.; Jensen, P.K.; Wong, Y.H.H.; Jiang, J.; Venkatramesh, M.; Gruys, K.J.; Moshiri, F.; et al. Metabolically engineered oilseed crops with enhanced seed tocopherol. Metab. Eng. 2005, 7, 384-400. [CrossRef] [PubMed]

57. Prabhu, P.R.; Hudson, A.O. Identification and partial characterization of an L-tyrosine aminotransferase (TAT) from Arabidopsis thaliana. Biochem. Res. Int. 2010, 549572. [CrossRef]

58. Grossmann, K.; Hutzler, J.; Tresch, S.; Christiansen, N.; Looser, R.; Ehrhardt, T. On the mode of action of the herbicides cinmethylin and 5-benzyloxymethyl-1,2-isoxyzolines: Putative inhibitors of plant tyrosine aminotransferase. Pest Manag. Sci. 2012, 68, 482-492. [CrossRef] [PubMed]

59. Riewe, D.; Koohi, M.; Lisec, J.; Pfeiffer, M.; Lippmann, R.; Schmeichel, J.; Willmitzer, L.; Altmann, T. A tyrosine aminotransferase involved in tocopherol synthesis in Arabidopsis. Plant J. 2012, 71, 850-859. [CrossRef] [PubMed]

60. Wang, M.; Toda, K.; Maeda, H.A. Biochemical properties and subcellular localization of tyrosine aminotransferases in Arabidopsis thaliana. Phytochemistry 2016, 132, 16-25. [CrossRef] [PubMed]

61. Garcia, I.; Rodgers, M.; Pepin, R.; Hsieh, T.Z.; Matringe, M. Characterization and subcellular compartmentation of recombinant 4-hydroxyphenylpyruvate dioxygenase from Arabidopsis in transgenic tobacco. Plant Physiol. 1999, 119, 1507-1516. [CrossRef] [PubMed]

62. Falk, J.; Krauss, N.; Dähnhardt, D.; Krupinska, K. The senescence associated gene of barley encoding 4-hydroxyphenylpyruvate dioxygenase is expressed during oxidative stress. J. Plant. Physiol. 2002, 159, 1245-1253. [CrossRef]

63. Siehl, D.L.; Tao, Y.; Albert, H.; Dong, Y.; Heckert, M.; Madrigal, A.; Lincoln-Cabatu, B.; Lu, J.; Fenwick, T.; Bermudez, E.; et al. Broad 4-hydroxyphenylpyruvate dioxygenase inhibitor herbicide tolerance in soybean with an optimized enzyme and expression cassette. Plant Physiol. 2014, 166, 1162-1176. [CrossRef] [PubMed]

64. Stacey, M.G.; Cahoon, R.E.; Nguyen, H.T.; Cui, Y.; Sato, S.; Nguyen, C.T.; Phoka, N.; Clark, K.M.; Liang, Y.; Forrester, J.; et al. Identification of homogentisate dioxygenase as a target for vitamin E biofortification in oilseeds. Plant Physiol. 2016, 172, 1506-1518. [CrossRef] [PubMed]

65. Widhalm, J.R.; Gutensohn, M.; Yoo, H.; Adebesin, F.; Qian, Y.; Guo, L.; Jaini, R.; Lynch, J.H.; McCoy, R.M.; Shreve, J.T.; et al. Identification of a plastidial phenylalanine exporter that influences flux distribution through the phenylalanine biosynthetic network. Nat. Commun. 2015, 6, 8142-8152. [CrossRef] [PubMed]

66. Rippert, P.; Scimemi, C.; Dubald, M.; Matringe, M. Engineering plant shikimate pathway for production of tocotrienol and improving herbicide resistance. Plant Physiol. 2004, 134, 92-100. [CrossRef] [PubMed]

67. Graebner, R.C.; Wise, M.; Cuesta-Marcos, A.; Geniza, M.; Blake, T.; Blake, V.C.; Butler, J.; Chao, S.; Hole, D.J.; Horsley, R.; et al. Quantitative trait loci associated with the tocochromanol (vitamin E) pathway in barley. PLoS ONE 2015, 10, e0133767. [CrossRef] [PubMed]

68. Diepenbrock, C.H.; Kandianis, C.B.; Lipka, A.E.; Magallanes-Lundback, M.; Vaillancourt, B.; Góngora-Castillo, E.; Wallace, J.G.; Cepela, J.; Mesberg, A.; Bradbury, P.J.; et al. Novel loci underlie natural variation in vitamin E levels in maize grain. Plant Cell 2017, 29, 2374-2392. [CrossRef] [PubMed]

69. Block, A.; Fristedt, R.; Rogers, S.; Kumar, J.; Barnes, B.; Barnes, J.; Elowsky, C.G.; Wamboldt, Y.; Mackenzie, S.A.; Redding, K.; et al. Functional modelling identifies paralogous solanesyl-diphosphate synthases that assemble the side chain of plastoquinone-9 in plastids. J. Biol. Chem. 2013, 288, 27594-27606. [CrossRef] [PubMed]

70. Hirooka, K.; Bamba, T.; Fukusaki, E.-I.; Kobayashi, A. Cloning and kinetic characterization of Arabidopsis thaliana solanesyl diphosphate synthase. Biochem. J. 2003, 370, 679-686. [CrossRef] [PubMed]

71. Hirooka, K.; Izumi, Y.; An, C.-I.; Nakazawa, Y.; Fukusaki, E.-I.; Kobayashi, A. Functional analysis of two solanesyl diphosphate synthases from Arabidopsis thaliana. Biosci. Biotechnol. Biochem. 2005, 69, 592-601. [CrossRef] [PubMed]

72. Eugeni Piller, L.; Besagnia, C.; Ksas, B.; Rumeau, D.; Bréhélin, C.; Glauser, G.; Kessler, F.; Havaux, M. Chloroplast lipid droplet type II NAD $(\mathrm{P}) \mathrm{H}$ quinone oxidoreductase is essential for prenylquinone metabolism and vitamin K1 accumulation. Proc. Natl. Acad. Sci. USA 2011, 108, 14354-14359. [CrossRef] [PubMed]

73. Grütter, C.; Alonso, E.; Chougnet, A.; Woggon, W.D. A biomimetic chromanol cyclization leading to $\alpha$-tocopherol. Angew. Chem. Int. Ed. 2006, 45, 1126-1130. [CrossRef] [PubMed]

74. Martinis, J.; Glauser, G.; Valimareanu, S.; Kessler, F. A chloroplast ABC1-like kinase regulates vitamin E metabolism in Arabidopsis. Plant Physiol. 2013, 162, 652-662. [CrossRef] [PubMed] 
75. Martinis, J.; Glauser, G.; Valimareanu, S.; Stettler, M.; Zeeman, S.C.; Yamamoto, H.; Shikanai, T.; Kessler, F. ABC1K1/PGR6 kinase: A regulatory link between photosynthetic activity and chloroplast metabolism. Plant J. 2014, 77, 269-283. [CrossRef] [PubMed]

76. Lundquist, P.K.; Poliakov, A.; Giacomelli, L.; Friso, G.; Appel, M.; McQuinn, R.P.; Krasnoff, S.B.; Rowland, E.; Ponnala, L.; Sun, Q.; et al. Loss of plastoglobule kinases ABC1K1 and ABC1K3 causes conditional degreening, modified prenyl-lipids, and recruitment of the jasmonic acid pathway. Plant Cell 2013, 25, 1818-1839. [CrossRef] [PubMed]

77. Kim, E.-H.; Lee, Y.; Kim, H.U. Fibrillin 5 is essential for plastoquinone-9 biosynthesis by binding to solanesyl diphosphate synthases in Arabidopsis. Plant Cell 2015, 27, 2956-2971. [CrossRef] [PubMed]

78. Kim, E.-H.; Lee, D-W.; Lee, K-R.; Jung, S-J.; Jeon, J-S.; Kim, H.U. Conserved function of fibrillin5 in the plastoquinone-9 biosynthetic pathway in Arabidopsis and rice. Front. Plant Sci. 2017, 8, 1197. [CrossRef] [PubMed]

79. Ischebeck, T.; Zbierzak, A.M.; Kanwischer, M.; Dormann, M. A salvage pathway for phytol metabolism in Arabidopsis. J. Biol. Chem. 2006, 281, 2470-2477. [CrossRef] [PubMed]

80. Valentin, H.; Lincoln, K.; Moshiri, F.; Jensen, P.K.; Qi, Q.; Venkatesh, T.V.; Karunanandaa, B.; Baszis, S.R.; Norris, S.R.; Savidge, B.; et al. The Arabidopsis vitamin E pathway gene5-1 mutant reveals a critical role for phytol kinase in seed tocopherol biosynthesis. Plant Cell 2006, 18, 212-224. [CrossRef] [PubMed]

81. Almeida, J.; da Silva Azevedo, M.; Spicher, L.; Glauser, G.; vom Dorp, K.; Guyer, L.; del Valle Carranza, A.; Asis, R.; Pereira de Souza, A.; Buckeridge, M.; et al. Down-regulation of tomato PHYTOL KINASE strongly impairs tocopherol biosynthesis and affects prenyllipid metabolism in an organ-specific manner. J. Exp. Bot. 2016, 67, 919-934. [CrossRef] [PubMed]

82. Zhang, C.; Zhang, W.; Ren, G.; Li, D.; Cahoon, R.E.; Chen, M.; Zhou, Y.; Yu, B.; Cahoon, E.B. Chlorophyll synthase under epigenetic surveillance is critical for vitamin E synthesis, and altered expression affects tocopherol levels in Arabidopsis. Plant Physiol. 2015, 168, 1503-1511. [CrossRef] [PubMed]

83. Vom Dorp, K.; Hölzl, G.; Plohmann, C.; Eisenhut, M.; Abraham, M.; Weber, A.P.M.; Hanson, A.D.; Dörmann, P. Remobilization of phytol from chlorophyll degradation is essential for tocopherol synthesis and growth of Arabidopsis. Plant Cell 2015, 27, 2846-2859. [CrossRef] [PubMed]

84. Cernac, A.; Benning, C. WRINKLED1 encodes an AP2/EREB domain protein involved in the control of storage compound biosynthesis in Arabidopsis. Plant J. 2004, 40, 575-585. [CrossRef] [PubMed]

85. Baud, S.; Santos Mendoza, M.; To, A.; Harscoët, E.; Lepiniec, L.; Dubreucq, B. WRINKLED1 specifies the regulatory action of LEAFY COTYLEDON2 towards fatty acid metabolism during seed maturation in Arabidopsis. Plant J. 2007, 50, 825-838. [CrossRef] [PubMed]

86. Focks, N.; Benning, C. wrinkled1: A novel, low-seed-oil mutant of Arabidopsis with a deficiency in the seed-specific regulation of carbohydrate metabolism. Plant Physiol. 1998, 118, 91-101. [CrossRef] [PubMed]

87. Ruuska, S.A.; Girke, T.; Benning, C.; Ohlrogge, J.B. Contrapuntal networks of gene expression during Arabidopsis seed filling. Plant Cell 2002, 14, 1191-1206. [CrossRef] [PubMed]

88. Maeo, K.; Tokuda, T.; Ayame, A.; Mitsui, N.; Kawai, T.; Tsukagoshi, H.; Ishiguro, S.; Nakamura, K. An AP2-type transcription factor, WRINKLED1, of Arabidopsis thaliana binds to the AW-box sequence conserved among proximal upstream regions of genes involved in fatty acid synthesis. Plant J. 2009, 60, 476-487. [CrossRef] [PubMed]

89. Pouvreau, B.; Baud, S.; Vernoud, V.; Morin, V.; Py, C.; Gendrot, G.; Pichon, J.-P.; Rouster, J.; Paul, W.; Rogowsky, P.M. Duplicate maize Wrinkled1 transcription factors activate target genes involved in seed oil biosynthesis. Plant Physiol. 2011, 156, 674-686. [CrossRef] [PubMed]

90. Grimberg, Å.; Carlsson, A.S.; Marttila, S.; Bhalerao, R.; Hofvander, P. Transcriptional transitions in Nicotiana benthamiana leaves upon induction of oil synthesis by WRINKLED1 homologs from diverse species and tissues. BMC Plant Biol. 2015, 15, 192. [CrossRef] [PubMed]

91. Banerjee, A.; Sharkey, T.D. Methylerythritol 4-phosphate (MEP) pathway metabolic regulation. Nat. Prod. Rep. 2014, 31, 1043-1055. [CrossRef] [PubMed]

(C) 2017 by the author. Licensee MDPI, Basel, Switzerland. This article is an open access article distributed under the terms and conditions of the Creative Commons Attribution (CC BY) license (http:/ / creativecommons.org/licenses/by/4.0/). 